\title{
Benchmarking public health pain management practices during school immunizations
}

\author{
Lucie M Bucci ${ }^{1 \star}$, Noni E MacDonald ${ }^{2,3}$, Tamlyn Freedman ${ }^{4,5}$, Anna Taddio ${ }^{4,5}$
}

\begin{abstract}
Background: Pain and fear during immunizations can affect children and their future behaviour toward immunization. These negative experiences can be amplified when children receive vaccines as part of school-based immunization programs, where parental or tutor supports are missing. In 2015, HELPinKIDS\&ADULTS, a Canadian network of experts, published a clinical practice guideline (CPG) on the management of pain and fear during immunization. This guideline has been endorsed by international, national and provincial organizations. However, the level of integration and implementation of the CPG into local and community immunization programs such as school-based immunization clinics is unclear.
\end{abstract}

Methods: An investigation whether public health units in Ontario integrated and implemented the pain and fear interventions recommended by the CPG into school-based immunization policies and practices was concluded.

Results: The study shows that the majority of public health units do have pain and fear policies and procedures in place, but interventions are not integrated in a consistent and formal manner, leading to suboptimal uptake of interventions during immunizations at school.

Conclusion: For pain interventions to be applied with sufficient fidelity and in enough individuals to have a meaningful effect, organizational leaders need to create directives and procedures that support implementation in a systematic and accountable manner.
This work is licensed under a Creative Commons Attribution 4.0 International License.

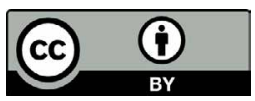

Affiliations

1 Immunize Canada, Canadian Public Health Association, Ottawa, ON

2 Department of Pediatrics, Faculty of Medicine, Dalhousie University, Halifax, NS

${ }^{3}$ IWK Health Centre, Halifax, NS

${ }^{4}$ Leslie Dan Faculty of Pharmacy, University of Toronto, Toronto, ON

${ }^{5}$ The Hospital for Sick Children, Toronto, ON

\section{*Correspondence:}

Ibucci@cpha.ca

Suggested citation: Bucci LM, MacDonald NE, Freedman T, Taddio A. Benchmarking public health pain management practices during school immunizations. Can Commun Dis Rep 2020;46(10):367-72.

https://doi.org/10.14745/ccdr.v46i10a10

Keywords: immunization, school programs, public health, pain, fear, clinical practice guideline, vaccine hesitancy

\section{Introduction}

Immunizing students at school is an effective way to increase immunization coverage. All public health jurisdictions in Canada have mass school-based programs that roll out vaccines against invasive meningococcal disease (IMD), hepatitis $B$ and human papillomavirus (HPV), among others. The positive outcomes of these programs are numerous. For example, vaccines given at school improve completion of multiple-dose regimens and provide well-timed immunizations relative to when protection is needed (1). In addition, vaccines delivered on time reduce the risk of infection and negative health outcomes.

A substantial number of students who receive vaccines at school have negative experiences; such reactions may lead to future vaccine refusal (2). These negative experiences are often related to pain and a fear of needles. As many as two out of three individuals are afraid of needle pain (3). Students who experience fear may have episodes of fainting, headaches, nausea and other symptoms. Such immunization stress-related responses may occur in clusters and, if not managed well, may undermine trust in immunization programs (4).

Evidence-based interventions exist to mitigate negative experiences due to pain and fear during immunizations. In 2015, HELPinKIDS\&ADULTS, a Canadian network of experts, published a clinical practice guideline (CPG) on the management of pain and fear during immunization (5). The World Health Organization (WHO) has recognized the guideline and referenced it in its first global policy paper on reducing pain at the time of immunization (6). More recently, the Public Health Agency of Canada integrated the guideline into the Canadian Immunization Guide (7). In addition, both the Ontario Ministry of Health and Long-Term Care (MOHLTC) and the BC Centre for Disease Control (BCCDC) adopted the guideline into their immunization policies and procedures $(8,9)$. 
While the guideline has been endorsed at the international, national and provincial levels, it is unclear how many public health units have integrated and implemented the CPG recommendations into their school-based immunization programs.

Since school immunization programs are carried out at the local level, it is important to explore what local public health units are doing to fully integrate and implement the guideline. There is little doubt that making broad practice changes in public health takes time. Readiness to change may also not be present at the local and/or community levels.

In 2015, MOHLTC published a roadmap for improving immunization in the province. This plan identified the 2015 CPG as an evidence-based approach for improving the immunization experience, strengthening vaccine delivery and reducing barriers to immunization (10).

To understand the status of CPG implementation, we undertook a benchmarking survey to document pain management practices and barriers and facilitators to CPG uptake by public health units across Ontario.

\section{Methods}

During the timeframe of our survey (September 2017 to March 2019), the school-based immunization program in Ontario delivered three vaccines to Grade 7 students: a one-dose regimen of the meningococcal vaccine and two doses of the hepatitis $B$ and HPV vaccines. A research team member from Immunize Canada emailed an invitation to a contact at each public health unit to identify a staff member familiar with school immunization policies and practices and qualified to answer the survey. The contact was identified from a list maintained by Immunize Canada and verified by MOHLTC. Using a structured telephone interview, a trained interviewer conducted the survey and questioned the identified staff member from each unit (i.e. a public health nurse, vaccine-preventable disease manager, supervisor, or director of immunization clinics).

The interview guide was designed according to standard survey construction guidelines. The guide included 53 questions in binary, multiple-choice and open-ended formats. Questions probed the following domains: presence of policies regarding school immunizations; consenting processes; staff and student training about how to cope with pain and fear during injection; coping interventions used during immunization clinics; assessment of student symptoms (pain, fear) and satisfaction; perceived barriers to pain mitigation; and characteristics of the unit (i.e. size of population served). The survey took approximately 45 to 60 minutes.
The survey was pretested with members of the Canadian Nurses Coalitions on Immunization $(\mathrm{CNCl})$. This national coalition of nurses from the public health sector and provincial health ministries is familiar with policy and procedures in school immunization programs.

Ethical approval was obtained from the IWK Health Centre Research Ethics Board.

\section{Results}

Of the 36 eligible public health units, individuals from 24 units participated in the survey. Six respondents (25\%) were from public health units that served a population of 500,000 or more.

The responses from the different survey domains are summarized in Table 1. All respondents stated that their public health unit had a local policy to oversee planning, implementation and reporting of immunization practices in schools. In addition, 14 of 24 (58\%) individuals reported that their unit had pain and fear management policies in place. The majority of respondents $(n=19 ; 79 \%)$ indicated that they formally educate students ahead of school clinics. This education typically includes the rationale for immunization, how vaccines work and their potential side effects. None of the respondents reported providing information to students about how to cope with needle pain or fear.

Coping interventions were inconsistently applied during immunization clinics (Table 2). While the majority of respondents reported using various coping interventions, less than half reported "always" or "almost always" using coping interventions

Table 1: Characteristics of school immunization programs in Ontario public health units $(n=24)$

\begin{tabular}{|l|r|}
\multicolumn{1}{|c|}{ Survey topic } & $\begin{array}{c}\text { Number that } \\
\text { responded "yes" }\end{array}$ \\
\hline Have school immunization policies on: & 24 \\
\hline Vaccine delivery process & 24 \\
\hline Anaphylaxis management & 24 \\
\hline Clinic procedures & 22 \\
\hline Fainting management & 19 \\
\hline $\begin{array}{l}\text { Education and communication with } \\
\text { students }\end{array}$ & 18 \\
\hline $\begin{array}{l}\text { Education and communication with school } \\
\text { staffa }\end{array}$ & 14 \\
\hline Pain and fear management & 12 \\
\hline Program evaluation/quality & 20 \\
\hline Have consenting procedures & 1 \\
\hline Sent home with students & 1 \\
\hline Mailed to parents & 2 \\
\hline $\begin{array}{l}\text { Accept student consent from high school } \\
\text { students }\end{array}$ & \\
\hline Other: not explained & \\
\hline
\end{tabular}


Table 1: Characteristics of school immunization programs in Ontario public health units $(n=24)$ (continued)

$$
\text { Survey topic }
$$

Have student education prior to immunization clinic $^{b}$

Reason for vaccine, how it works and side effects

Reason for vaccine, how it works, side effects and exemptions

Reason for vaccine, how it works, side effects, logistics of vaccine day and website for Q\&A

Reason for vaccine, how it works, side effects, risks and benefits

Reason for vaccine and side effects

Have formal training for public health staff on:

Anaphylaxis treatment ${ }^{\mathrm{a}}$

Fainting mitigation

Program delivery ${ }^{a}$

Communication with school staffa

Communication with students ${ }^{a}$

Pain mitigation ${ }^{\text {a }}$

12

Fear/anxiety mitigation

Monitor students during immunization clinics for:

Student preferences for coping strategies ${ }^{a}$

Documented in computer database

Documented manually

Student experience with immunization ${ }^{a}$

No written record of how specified

Fear

Informal description (not documented) of how specified

Pain $^{\text {a }}$

Informal description (not documented) of how specified

Computer database

No answer

Abbreviation: Q\&A, questions and answers

${ }^{a} \mathrm{n}=1$ missing

${ }^{\mathrm{b}} \mathrm{n}=2$ missing

except for verbal distraction, comfortable seating, short wait times and vaccinating most fearful students first. Few respondents solicited student coping preferences, overall immunization experience or injection-related symptoms (pain, fear).

Respondents identified several challenges that affected the implementation of pain and fear mitigation interventions. These included budget constraints and physical space constraints
Table 2: Pain and fear interventions applied by public health units in Ontario $(n=24)$

\begin{tabular}{|c|c|c|c|}
\hline Intervention & $\begin{array}{c}\text { Number } \\
\text { that use } \\
\text { intervention }\end{array}$ & \multicolumn{2}{|c|}{$\begin{array}{l}\text { Frequency of use of } \\
\text { the intervention }\end{array}$} \\
\hline \multirow{6}{*}{$\begin{array}{l}\text { Distraction with } \\
\text { personal items } \\
\text { Personal items used } \\
\text { include personal } \\
\text { mobile phone }(n=21) \\
\text { and/or other object } \\
(n=1)\end{array}$} & \multirow{6}{*}{22} & Always & 6 \\
\hline & & Almost always & 4 \\
\hline & & Sometimes & 9 \\
\hline & & Almost never & 1 \\
\hline & & Never & 0 \\
\hline & & No answer & 2 \\
\hline \multirow{6}{*}{ Verbal distraction ${ }^{a}$} & \multirow{6}{*}{23} & Always & 8 \\
\hline & & Almost always & 5 \\
\hline & & Sometimes & 3 \\
\hline & & Almost never & 0 \\
\hline & & Never & 0 \\
\hline & & No answer & 5 \\
\hline \multirow{6}{*}{$\begin{array}{l}\text { Sitting in a comfortable } \\
\text { position }^{a}\end{array}$} & \multirow{6}{*}{20} & Always & 11 \\
\hline & & Almost always & 2 \\
\hline & & Sometimes & 0 \\
\hline & & Almost never & 1 \\
\hline & & Never & 0 \\
\hline & & No answer & 6 \\
\hline \multirow{6}{*}{ Short wait times ${ }^{a}$} & \multirow{6}{*}{18} & Always & 10 \\
\hline & & Almost always & 5 \\
\hline & & Sometimes & 3 \\
\hline & & Almost never & 0 \\
\hline & & Never & 0 \\
\hline & & No answer & 0 \\
\hline \multirow{6}{*}{$\begin{array}{l}\text { Presence of peer } \\
\text { support }^{\mathrm{b}}\end{array}$} & \multirow{6}{*}{18} & Always & 0 \\
\hline & & Almost always & 6 \\
\hline & & Sometimes & 8 \\
\hline & & Almost never & 1 \\
\hline & & Never & 0 \\
\hline & & No answer & 3 \\
\hline \multirow{6}{*}{$\begin{array}{l}\text { Privacy } \\
\text { Approaches used } \\
\text { for providing privacy } \\
\text { depends on the school } \\
\text { ( } n=6) \text { and include using } \\
\text { a private room ( } n=5) \text {, } \\
\text { immunizing students } \\
\text { at the beginning or } \\
\text { end of clinic ( } n=3 \text { ) and } \\
\text { using a privacy screen } \\
(n=1)\end{array}$} & \multirow{6}{*}{17} & Always & 6 \\
\hline & & Almost always & 1 \\
\hline & & Sometimes & 6 \\
\hline & & Almost never & 3 \\
\hline & & Never & 0 \\
\hline & & No answer & 1 \\
\hline
\end{tabular}


Table 2: Pain and fear interventions applied by public health units in Ontario $(n=24)$ (continued)

\begin{tabular}{|c|c|c|c|}
\hline Intervention & $\begin{array}{c}\text { Number } \\
\text { that use } \\
\text { intervention }\end{array}$ & \multicolumn{2}{|c|}{$\begin{array}{l}\text { Frequency of use of } \\
\text { the intervention }\end{array}$} \\
\hline \multirow{6}{*}{$\begin{array}{l}\text { Use of topical } \\
\text { anesthetics }^{a}\end{array}$} & \multirow{6}{*}{16} & Always & 0 \\
\hline & & Almost always & 0 \\
\hline & & Sometimes & 3 \\
\hline & & Almost never & 10 \\
\hline & & Never & 0 \\
\hline & & No answer & 3 \\
\hline \multirow{6}{*}{$\begin{array}{l}\text { Vaccinate most fearful } \\
\text { first }^{a}\end{array}$} & \multirow{6}{*}{15} & Always & 8 \\
\hline & & Almost always & 3 \\
\hline & & Sometimes & 2 \\
\hline & & Almost never & 1 \\
\hline & & Never & 0 \\
\hline & & No answer & 1 \\
\hline \multirow{6}{*}{$\begin{array}{l}\text { Distraction provided by } \\
\text { public health } \\
\text { Examples of items used } \\
\text { include juice box, stress } \\
\text { ball, toys (e.g. bubbles, } \\
\text { pinwheels, stuffed } \\
\text { animals), books }\end{array}$} & \multirow{6}{*}{12} & Always & 2 \\
\hline & & Almost always & 1 \\
\hline & & Sometimes & 4 \\
\hline & & Almost never & 1 \\
\hline & & Never & 0 \\
\hline & & No answer & 4 \\
\hline
\end{tabular}

in schools. In addition, respondents reported being unable to negotiate optimal clinic spaces in schools because of poor relationships with school administrators.

\section{Discussion}

Implementing interventions proven to alleviate pain and fear during school immunization clinics requires integration across immunization policies and practices and collaboration among all stakeholders (public health, school staff, students, parents). At present, the CPG recommendations appear to be insufficiently integrated into clinic planning and delivery activities. This limits frontline staff in their ability to implement different types of pain interventions at the required frequency.

To achieve broader and more consistent use of interventions, we recommend that public health leaders and policy and program managers develop policies and procedures that explicitly incorporate pain mitigation interventions into immunization clinic planning and delivery activities and track student symptoms as a quality indicator for their programs.

A vaccine delivery framework, the CARD ${ }^{\mathrm{TM}}$ system, was developed to help facilitate the integration of the CPG in the school immunization program (11). Each letter of the word "card" encompasses a category of evidence-based interventions (C - Comfort, A - Ask, R - Relax, D - Distract) to reduce pain, fear and fainting. All these interventions can be used ahead of time to prepare students for the procedure.

The CARD ${ }^{\text {TM }}$ system provides a systematic approach to planning, delivering and monitoring school-based immunizations. The system incorporates student needs and preferences, promoting student-centred care and health equity (12). The program includes, for example, meeting with school principals ahead of time to identify suitable clinic spaces, setting up clinic spaces to minimize cues that elicit fear, and asking students to report on their symptoms.

To be successful, CARD TM requires the backing of organizational leaders who create policies and procedures to support implementation. Education and training of all the relevant stakeholders is also required so that they are versed in and committed to the program and can deliver it with fidelity (13).

To date, CARD ${ }^{\text {TM }}$ has been evaluated in one public health unit in Ontario, Niagara Region Public Health, where it was demonstrated to reduce student fear and dizziness (a precursor of fainting) during school-based immunizations (14). After the evaluation, CARD ${ }^{\mathrm{TM}}$ was implemented across the unit's entire school immunization program.

There are several potential benefits to addressing pain and fear during school immunizations. First, students will have more positive immunization experiences because they will have less pain and fear. Second, utilizing pain and fear mitigation strategies equips students with coping skills that may be applied to other stressful situations. Third, by reducing pain and fear, nurses demonstrate both competence and caring, qualities needed to develop trusting relationships. Long term, students may develop more positive attitudes about immunization and healthcare providers, which may lead to higher acceptance of vaccines and other healthcare interventions, in turn leading to improved health outcomes (15).

\section{Limitations}

There are a few shortcomings that should be acknowledged, including changes in practices over time, potential errors in measurement and potential errors in data interpretation. The study took place between 2017 and 2019, and it is possible that some public health unit practices changed after participation in this study. For instance, as previously stated, a public health unit that participated in the development of CARD ${ }^{\mathrm{TM}}$ subsequently implemented it across the entire school program in 2019.

In addition, participants self-reported practices and may have introduced random error and bias (e.g. social desirability bias) into their responses. However, given that the results 
demonstrated low uptake of CPG recommendations in general, it is unlikely that bias contributed to a significant source of error.

Finally, the design of the study does not allow for estimating the actual utilization rates of specific pain interventions, and responses may inadvertently be interpreted as actual use. For instance, while most respondents indicated they use personal distraction items almost always or always, this intervention requires students to come to school with these items in hand. Given that students and their families are not informed ahead of time about being able to use personal distraction devices during immunization clinics, it is likely that many do not actually bring anything to distract themselves.

\section{Conclusion}

This survey of Ontario public health units demonstrated limited integration and implementation of the immunization pain mitigation CPG into school clinic practice at the local level. While the majority of public health units have policies and procedures on pain and fear management, they do not appear to be put into action in a formal way by the public health staff. This leads to inconsistent and suboptimal integration of pain interventions in the school immunization program. For pain interventions to be applied with sufficient fidelity and in enough individuals to have a meaningful effect, organizational leaders need to create directives and procedures that support implementation in a systematic and accountable manner.

\section{Authors' statement}

LMB - Project administration, supervision, investigation, data curation, formal analysis, writing original draft NEM - Conceptualization, writing-review and editing

TF - Data curation, writing-review and editing AT - Conceptualization, methodology, supervision, writing-review and editing

\section{Competing interests}

This study originated at the Canadian Public Health Association/Immunize Canada with collaborators from the University of Toronto and Dalhousie University. There are no other disclosures.

\section{Acknowledgements}

The authors would like to thank the individuals who participated in this study, the HELPinKIDS\&ADULTS team, and L Lee and $R$ Segall for their contribution.

\section{Funding}

AT reports Section 9 Trademark No. 924835 for CARD.

LMB reports that Immunize Canada received grants from Pfizer Canada, Merck Canada, GSK Canada, Seqirus Canada and Sanofi Pasteur outside the submitted work.

\section{References}

1. Perman S, Turner S, Ramsay Al, Baim-Lance A, Utley M, Fulop NJ. School-based vaccination programmes: a systematic review of the evidence on organisation and delivery in high income countries. BMC Public Health 2017 Mar;17(1):252-64. DOI PubMed

2. Taddio A, Chambers CT, Halperin SA, Ipp M, Lockett D, Rieder MJ, Shah V. Inadequate pain management during routine childhood immunizations: the nerve of it. Clin Ther 2009;31 Suppl 2:S152-67. DOI PubMed

3. Taddio A, Ipp M, Thivakaran S, Jamal A, Parikh C, Smart S, Sovran J, Stephens D, Katz J. Survey of the prevalence of immunization non-compliance due to needle fears in children and adults. Vaccine 2012 Jul;30(32):4807-12. DOI PubMed

4. Gold MS, MacDonald NE, McMurtry CM, Balakrishnan MR, Heininger U, Menning L, Benes O, Pless R, Zuber PL. Immunization stress-related response - Redefining immunization anxiety-related reaction as an adverse event following immunization. Vaccine 2020 Mar;38(14):3015-20. DOl PubMed

5. Taddio A, McMurtry CM, Shah V, Riddell RP, Chambers CT, Noel M, MacDonald NE, Rogers J, Bucci LM, Mousmanis $P$, Lang E, Halperin SA, Bowles S, Halpert C, Ipp M, Asmundson GJ, Rieder MJ, Robson K, Uleryk E, Antony MM, Dubey V, Hanrahan A, Lockett D, Scott J, Bleeker EV; HELPinKids\&Adults. Reducing pain during vaccine injections: clinical practice guideline. CMAJ 2015 Sep;187(13):975-82. DOI PubMed

6. World Health Organization. Meeting of the Strategic Advisory Group of Experts on immunization, April 2015: Conclusions and recommendations [WER]. Wkly Epidemiol Rec 2015 May;90(22):261-78. https://www.who.int/ wer/2015/wer9022.pdf?ua=1

7. Public Health Agency of Canada. Vaccination administration practices: Canadian immunization guide. Table 4: Immunization pain management strategies, by age groups. Ottawa (ON): Public Health Agency of Canada (modified 2017-11-03; accessed 2020-07-13). https://www.canada. ca/en/public-health/services/publications/healthy-living/ canadian-immunization-guide-part-1-key-immunizationinformation/page-8-vaccine-administration-practices.html\#t4 
8. Ontario Ministry of Health and Long-Term Care (MOHLTC). Vaccines: the best medicine: 2014 Annual Report of the Chief Medical Officer of Health of Ontario to the Legislative Assembly of Ontario. Toronto (ON): Queen's Printer for Ontario; 2016. Catalogue No.: 020369 ISSN 1920-9304. www.health.gov.on.ca/en/common/ministry/publications/ reports/cmoh_14_vaccines/docs/cmoh_14_vaccines.pdf

9. BC Centre for Disease Control. Communicable Disease Control Manual, Chapter 2: Immunization. Appendix D - reducing immunization injection pain. Vancouver $(B C)$ : BCCDC; 2018-12. http://www.bccdc.ca/resource-gallery/ Documents/Guidelines\%20and\%20Forms/Guidelines\%20 and\%20Manuals/Epid/CD\%20Manual/Chapter\%202\%20 -\%20lmms/SectionIVB_RIIP.pdf

10. Ontario Ministry of Health and Long-Term Care. Ministry reports: Immunization 2020: modernizing Ontario's publicly funded immunization program. Toronto (ON): MOHLTC; 2015-12 (accessed 2020-07-15). http://www.health. gov.on.ca/en/common/ministry/publications/reports/ immunization_2020/

11. Taddio A. Pain Pain Go Away: improving the vaccination experience at school. Paediatr Child Health 2019 Apr;24 Suppl 1:S1-2. DOI PubMed

12. Taddio A, McMurtry CM, Bucci LM, MacDonald N, Ilersich AN, Ilersich AL, Alfieri-Maiolo A, deVlaming-Kot C, Alderman L; Pain Pain Go Away Team. Overview of a Knowledge Translation (KT) Project to improve the vaccination experience at school: the CARD ${ }^{\mathrm{TM}}$ System. Paediatr Child Health 2019 Apr;24 Suppl 1:S3-18. DOI PubMed
13. Taddio A, Alderman $L$, Freedman $T$, McDowall $T$, McMurtry CM, MacDonald N, deVlaming-Kot C, Alfieri-Maiolo A; Pain Pain Go Away Team. The CARDTM System for improving the vaccination experience at school: results of a small-scale implementation project on program delivery. Paediatr Child Health 2019 Apr;24 Suppl 1:S54-67. DOI PubMed

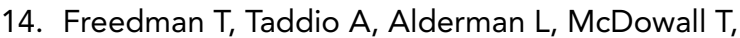
deVlaming-Kot C, McMurtry CM, MacDonald N, Alfieri-Maiolo A, Stephens D, Wong $\mathrm{H}$, Boon $\mathrm{H}$; Pain Pain Go Away Team. The CARDTM System for improving the vaccination experience at school: results of a small-scale implementation project on student symptoms. Paediatr Child Health 2019 Apr;24 Suppl 1:S42-53. DOI PubMed

15. Taddio A, Bucci LM, Logeman C, Gudzak V. The CARD ${ }^{T M}$ system: a patient-centred care tool to ease pain and fear during school vaccination. Ottawa (ON): CANVax; 2020-07-21 (accessed 2020-07-30). https://canvax.ca/brief/ cardtm-system-patient-centred-care-tool-ease-pain-and-fe ar-during-school-vaccinations 